\title{
THE
}

\section{FROM INDIVIDUALS TO ECOSYSTEM FUNCTION: TOWARD AN INTEGRATION OF EVOLUTIONARY AND ECOSYSTEM ECOLOGY}

\author{
Oswald J. Schmitz \\ Jonathan H. Garbowski \\ Barbara L. Peckarsky \\ Evan L. Preisser \\ University of California - Davis, preisser@uri.edu \\ Geoffrey C. Trussell
}

See next page for additional authors

Follow this and additional works at: https://digitalcommons.uri.edu/bio_facpubs

Terms of Use

All rights reserved under copyright.

\section{Citation/Publisher Attribution}

Schmitz, O. J., Grabowski, J. H., Peckarsky, B. L., Preisser, E. L., Trussell, G. C. and Vonesh, J. R. (2008), FROM INDIVIDUALS TO ECOSYSTEM FUNCTION: TOWARD AN INTEGRATION OF EVOLUTIONARY AND ECOSYSTEM ECOLOGY. Ecology, 89: 2436-2445. doi:10.1890/07-1030.1 Available at: https://doi.org/ 10.1890/07-1030.1

This Article is brought to you for free and open access by the Biological Sciences at DigitalCommons@URI. It has been accepted for inclusion in Biological Sciences Faculty Publications by an authorized administrator of DigitalCommons@URI. For more information, please contact digitalcommons-group@uri.edu. 


\section{Authors}

Oswald J. Schmitz, Jonathan H. Garbowski, Barbara L. Peckarsky, Evan L. Preisser, Geoffrey C. Trussell, and James R. Vonesh

This article is available at DigitalCommons@URI: https://digitalcommons.uri.edu/bio_facpubs/123 


\title{
FROM INDIVIDUALS TO ECOSYSTEM FUNCTION: TOWARD AN INTEGRATION OF EVOLUTIONARY AND ECOSYSTEM ECOLOGY
}

\author{
Oswald J. Schmitz, ${ }^{1,7}$ Jonathan H. Grabowski, ${ }^{2}$ Barbara L. Peckarsky, ${ }^{3}$ Evan L. Preisser, ${ }^{4}$ \\ Geoffrey C. Trussell, ${ }^{5}$ and James R. Vonesh ${ }^{6}$ \\ ${ }^{1}$ School of Forestry and Environmental Studies, Yale University, New Haven, Connecticut 06511 USA \\ ${ }^{2}$ Gulf of Maine Research Institute, Portland, Maine 04101 USA \\ ${ }^{3}$ Department of Zoology, University of Wisconsin, Madison, Wisconsin 53706 USA \\ ${ }^{4}$ Department of Biological Sciences, University of Rhode Island, Kingston, Rhode Island 02881 USA \\ ${ }^{5}$ Marine Science Center, Northeastern University, Nahant, Massachusetts 01908 USA \\ ${ }^{6}$ Department of Biology, Virginia Commonwealth University, Richmond, Virginia 23284-2012 USA
}

\begin{abstract}
An important goal in ecology is developing general theory on how the species composition of ecosystems is related to ecosystem properties and functions. Progress on this front is limited partly because of the need to identify mechanisms controlling functions that are common to a wide range of ecosystem types. We propose that one general mechanism, rooted in the evolutionary ecology of all species, is adaptive foraging behavior in response to predation risk. To support our claim, we present two kinds of empirical evidence from plantbased and detritus-based food chains of terrestrial and aquatic ecosystems. The first kind comes from experiments that explicitly trace how adaptive foraging influences ecosystem properties and functions. The second kind comes from a synthesis of studies that individually examine complementary components of particular ecosystems that together provide an integrated perspective on the link between adaptive foraging and ecosystem function. We show that the indirect effects of predators on plant diversity, plant productivity, nutrient cycling, trophic transfer efficiencies, and energy flux caused by consumer foraging shifts in response to risk are qualitatively different from effects caused by reductions in prey density due to direct predation. We argue that a perspective of ecosystem function that considers effects of consumer behavior in response to predation risk will broaden our capacity to explain the range of outcomes and contingencies in trophic control of ecosystems. This perspective also provides an operational way to integrate evolutionary and ecosystem ecology, which is an important challenge in ecology.
\end{abstract}

Key words: adaptive foraging; ecosystem function; nonconsumptive effects; nutrient cycling; predation risk; top-down control; trophic efficiencies; trophic interactions.

\section{INTRODUCTION}

Ecologists have long recognized that an ecosystem is a conceptualization of nature that considers both the biotic and the biophysical components of the environment as an integrated whole (Tansley 1935, Leopold 1939, Lindeman 1942). By tradition, however, ecological science has rarely taken an integrated approach to understanding how ecosystems work (Levin 1992). Ecosystem ecology has largely focused on biophysical properties (e.g., organic matter pool content, soil elemental content, trophic structure, and trophic transfer efficiencies) and functions (or processes) such as production, decomposition, and elemental cycling that determine energy and material flows through systems (DeAngelis 1992). Meanwhile, community ecology has largely focused on biotic interactions among species (e.g., predation, herbivory, competition, and mutualism)

Manuscript received 26 June 2007; revised 9 October 2007; accepted 7 November 2007. Corresponding Editor: S. Naeem. For reprints of this Special Feature, see footnote 1, p. 2414.

${ }^{7}$ E-mail: oswald.schmitz@yale.edu and emergent indirect interactions that determine the distribution and abundance of species within and among trophic levels (DeAngelis 1992).

Effort to reconnect these dichotomous approaches has been spurred by the increasing recognition that biotic interactions among species (as a consequence of their traits and functional roles) may be important mediators of biophysical properties and functions (Hairston and Hairston 1993, Chapin et al. 1997, 2000b, Hooper et al. 2005). Moreover, growing concern over how loss of biodiversity and ensuing changes in species composition will alter ecosystem properties and functions has led to increased interest in developing predictive theory that explicitly couples the dynamics of biotic and biophysical components of ecosystems (Levin 1992, Chapin et al. 1997, 2000b, Carpenter et al. 2006).

Developing such predictive theory requires identifying mechanisms controlling functions that are common to a wide range of ecosystem types. This task is challenging because there is wide variation in the spatial and temporal scale on which the dynamics of different 
ecosystems operate (Levin 1992, Carpenter and Turner 2000, Chapin et al. 2000a). In addition, mechanisms operating on one level of biological organization can affect function at higher organizational levels. As a result, the linkages between levels do not become fully apparent until pattern and process are examined simultaneously at several organizational levels (Levin 1992, Carpenter and Turner 2000). Understanding the connections between lower- and higher-level phenomena also requires identifying which of the many potentially important mechanisms can be safely abstracted and which must be explicitly examined (Levin 1992).

We propose that one important mechanism that should be considered more fully is the adaptive foraging behavior of species in intermediate trophic levels of ecosystems. This claim is based on several separate observations. First, the biotic part of an ecosystem can be universally envisioned as being composed of chains of consumers that are themselves resources for other consumers (Odum and Biever 1984, Paine 1988, Tilman 1989, Hairston and Hairston 1993). The simplest kinds of chains are either live plant-based, in which consumer species provide the link between plant resources and their predators or detrital-based, in which consumers link the organic matter pool to predators (Odum and Biever 1984, Hairston and Hairston 1993, Wardle 2002). Second, consumer adaptive foraging behavior, especially of herbivore species can influence the fate of primary production through the selective consumption of certain plant species. Such selectivity can change the quality and quantity of plant and fecal material entering the organic matter pool which, in turn, affects nutrient cycling rates (McInnes et al. 1992, Pastor et al. 1993, Ritchie et al. 1998, Belovsky and Slade 2000). Third, predators in ecosystems can have important indirect impacts not only on plant biomass (i.e., trophic cascades), but also on plant diversity and production, trophic transfer efficiencies, organic matter decomposition, and nutrient cycling (McPeek et al. 2001, Duffy 2003, Fukami et al. 2006, Greig and McIntosh 2006, Hargrave 2006, Maron et al. 2006, Schmitz 2006, Stief and Hölker 2006, Trussell et al. 2006b). Finally, intermediate species in trophic chains must often balance the trade-off between maximizing energy or nutrient acquisition and minimizing predation risk (Abrams 1984, 1992, Peckarsky et al. 1997, Werner and Peacor 2003, Schmitz et al. 2004, Preisser et al. 2005). Thus, from an evolutionary ecological perspective, any species subject to predation risk should respond adaptively to balance fitness gains from foraging with fitness losses from predation (Mangel and Clark 1988, Lima and Dill 1990, Lima 1998).

Our goal here is to highlight examples that illustrate how consideration of adaptive foraging can assist in resolving the causal link between biotic and abiotic ecosystem components and thereby help to develop predictive theory for ecosystem function. We achieve our goal in two ways. We begin by highlighting case studies that have demonstrated the link between adaptive foraging behavior of consumers and ecosystem function (Table 1). We then synthesize an array of studies that individually examine complementary components of particular ecosystems; when considered in combination, these studies provide an integrated perspective on the link between adaptive foraging and ecosystem function (Table 1). In so doing, we devise operational ways of blending evolutionary and ecosystem ecology, which is an important challenge in ecology (Oksanen 1988, Levin 1992, Holt 1995, Carpenter and Turner 2000).

\section{Case Studies: Providing Direct Evidence}

The following three case studies experimentally trace how nonconsumptive effects of predators caused by adaptive foraging of intermediate consumers influence important ecosystem properties and functions. The first two cases deal with indirect effects of predators that propagate down plant-based and detritus-based food chains to influence nutrient cycling and primary production. The third case deals with nonconsumptive indirect effects of top predators that propagate back up a food chain to influence trophic transfer efficiency and hence secondary production.

\section{Effects propagating along the live plant-based chain}

Long-term research in an old-field ecosystem has revealed that despite the wide diversity of species and complex network of species interdependencies, ecosystem function is determined by strong interactions among a few dominant species: the sit-and-wait hunting spider Pisuarina mira, the generalist grasshopper herbivore Melanoplus femurrubrum, the grass Poa pratensis, and the competitive dominant herb Solidago rugosa (Schmitz 2004). In this system, M. femurrubrum grasshoppers face a trade-off between selecting plant species to maximize nutritional intake and avoiding predation risk. The grasshoppers prefer $P$. pratensis in the absence of predators. Mortality from P. mira predators is comparatively low, but mortality risk caused by predator presence induces grasshoppers to switch from feeding on grass to seeking refuge in and foraging on the less nutritious S. rugosa (Schmitz 2004). Consequently, $P$. mira spiders exert most of their top-down control on the system by altering grasshopper foraging rather than grasshopper density. As a result, $P$. mira predators have a net positive indirect effect on abundance of grass and a net negative indirect effect on the abundance of the herb $S$. rugosa. These indirect effects of predators in turn lead to important effects on plant productivity, diversity, and the biophysical properties of the system itself. In the absence of predators, herbivores have a comparatively weak effect on the highly productive $S$. rugosa and allow it to grow rapidly into tall, dense stands that shade the surrounding soil. In the presence of predators, herbivore consumption both thins $S$. rugosa stands and stunts the height of the remaining stems, suppressing the most productive plant species in this ecosystem and creating a 
TABLE 1. Summary of studies demonstrating the link between consumer adaptive foraging in response to predation risk and ecosystem function.

\begin{tabular}{|c|c|c|c|c|c|c|c|c|c|c|}
\hline \multirow[b]{2}{*}{ System } & \multirow[b]{2}{*}{ Predators } & \multirow[b]{2}{*}{ Prey } & \multicolumn{8}{|c|}{ Predator indirect effects on ecosystem functions } \\
\hline & & & $\begin{array}{c}\text { Predator } \\
\text { direct effects } \\
\text { on prey }\end{array}$ & $\begin{array}{l}\text { Mineral- } \\
\text { ization/ } \\
\text { cycling }\end{array}$ & $\begin{array}{c}\text { Nutrient/ } \\
\text { resource } \\
\text { uptake }\end{array}$ & $\begin{array}{l}\text { Nutrient } \\
\text { flux }\end{array}$ & $\begin{array}{l}\text { Produc- } \\
\text { tivity/ } \\
\text { respiration }\end{array}$ & $\begin{array}{c}\text { Plant } \\
\text { decompo- } \\
\text { sition }\end{array}$ & $\begin{array}{l}\text { Trophic } \\
\text { efficiency }\end{array}$ & Source \\
\hline \multicolumn{11}{|l|}{ Direct evidence } \\
\hline $\begin{array}{l}\text { Terrestrial } \\
\text { old field }\end{array}$ & spiders & grasshoppers & habitat shift & $\uparrow$ & & & $\downarrow$ & & & 1 \\
\hline $\begin{array}{l}\text { Freshwater } \\
\text { mesocosm }\end{array}$ & fish & chironomids & $\begin{array}{l}\text { refuge use, } \\
\text { reduced } \\
\text { feeding }\end{array}$ & & & $\uparrow \uparrow$ & & & & 2 \\
\hline $\begin{array}{l}\text { Marine } \\
\text { mesocosm }\end{array}$ & $\begin{array}{l}\text { green } \\
\text { crabs }\end{array}$ & dogwhelks & $\begin{array}{l}\text { reduced } \\
\text { foraging }\end{array}$ & & & & & & $\downarrow$ & 3 \\
\hline \multicolumn{11}{|c|}{ Synthesis of complementary studies } \\
\hline $\begin{array}{l}\text { Freshwater } \\
\text { lakes }\end{array}$ & $\begin{array}{l}\text { cyprinid } \\
\text { fish }\end{array}$ & zooplankton & $\begin{array}{l}\text { diel vertical } \\
\text { migration }\end{array}$ & $\downarrow$ & & & & & & 4 \\
\hline $\begin{array}{l}\text { Freshwater } \\
\text { streams }\end{array}$ & $\begin{array}{l}\text { trout/ } \\
\quad \text { galaxiads }\end{array}$ & mayflies & $\begin{array}{l}\text { reduced } \\
\text { foraging }\end{array}$ & & $\uparrow \ddagger$ & & & & & 5 \\
\hline $\begin{array}{c}\text { Freshwater } \\
\text { streams }\end{array}$ & trout & mayflies & $\begin{array}{l}\text { reduced } \\
\text { oraging }\end{array}$ & & & $\uparrow \S$ & & & & 6 \\
\hline $\begin{array}{l}\text { Freshwater } \\
\text { streams }\end{array}$ & trout & amphipods & $\begin{array}{l}\text { reduced } \\
\text { foraging, } \\
\text { emigration }\end{array}$ & & & & & $\downarrow$ & & 7 \\
\hline $\begin{array}{l}\text { Freshwater } \\
\text { ponds }\end{array}$ & fish & $\begin{array}{l}\text { spotted } \\
\text { salamanders }\end{array}$ & $\begin{array}{l}\text { reduced } \\
\text { number of } \\
\text { eggs masses } \\
\text { laid }\end{array}$ & & & $\downarrow \uparrow$ & & & & 8 \\
\hline $\begin{array}{l}\text { Terrestrial } \\
\text { grassland }\end{array}$ & wolves & elk & habitat shift & $\downarrow$ & $\downarrow$ & & $\downarrow$ & & & 9 \\
\hline
\end{tabular}

Note: Sources are: 1, Schmitz (2004, 2006); 2, Stief and Hölker (2006); 3, Trussell et al. (2003, 2006a, b); 4, Knoechel and Holtby (1986), Dawidowicz and Loose (1992), Riessen (1999); 5, McIntosh and Townsend (1996), Simon et al. (2004); 6, Peckarsky and McIntosh (1998), McIntosh et al. (2004); B. W. Taylor, B. L. Peckarsky, and A. R. McIntosh, unpublished manuscript; 7, Andersson et al. (1986), Holomuzki and Hoyle (1990), Konishi et al. (2001); 8, Petranka and Holbrook (2006), Regester et al. (2006); 9 , Tracy and Frank (1998), Augustine and Frank (2001), Ripple and Beschta (2004), Creel et al. (2005), Fortin et al. (2005).

$\uparrow$ Nutrient transfer from sediment surface to water column.

\$ Shift in $\mathrm{N}$-uptake from grazers to surface algae.

$\S$ Altered export of organic matter up to $30 \mathrm{~m}$ downstream.

$\uparrow$ Increased export of biomass and energy flux.

more open and patchy environment. This effect leads to higher levels of photosynthetically active radiation (PAR) reaching the soil surface, which in turn facilitates the proliferation of other less productive herb species that are intolerant of shady conditions caused by $S$. rugosa. These conditions thereby enhance plant species diversity, measured as species evenness, but lower plant productivity (Schmitz 2004, 2006). The altered community structure also leads to changes in $\mathrm{N}$-mineralization rate. Solidago species produce litter that is recalcitrant to decomposition, leading to low soil $\mathrm{N}$ supply when they dominate. Decreases in S. rugosa abundance lead to rising supply rates of nitrogen in the system (Schmitz 2006).

The research previously described demonstrates that predator-induced changes in herbivore foraging behavior rather than herbivore density can generate an indirect keystone predation effect on a competitive dominant plant. That indirect effect produces an inverse relationship between plant species diversity and plant productivity because plant diversity was a by-product of a species interaction that altered plant dominance. This indirect effect also enhanced the supply rate of an important soil nutrient by altering mineralization rate. Moreover, the impact of these indirect effects on ecosystem properties and functions (PAR and $\mathrm{N}$ mineralization rate) were two to three times greater than the strength of indirect effects on the biotic components of the ecosystem, indicating that top-down effects intensified from the biotic to the biophysical level (Schmitz 2006).

The mechanisms of predator effects on prey were largely nonconsumptive (via changes in prey behavior), and notably the indirect effects on plant diversity, ecosystem properties, and ecosystem functioning are qualitatively different in sign than would be expected if predator effects on its prey were consumptive. In particular, another species of spider predator in the old-field system (a jumping spider that actively hunts its prey) primarily causes density reductions of $M$. femurrubrum grasshoppers, and these density effects override the effects of grasshopper diet switching (Schmitz and Suttle 2001). The consumptive effect of the jumping spiders leads to positive indirect effects on both $S$. rugosa and $P$. pratensis (Schmitz and Suttle 2001). This, in turn, should cause a reduction in plant diversity and PAR and a rise 
in plant productivity. These effects are opposite in sign to those described previously for the sit-and-wait predator species. This example illustrates that one could arrive at altogether incorrect conclusions about trophic effects on ecosystems if one assumed that consumptive effects of predators on their prey were the predominant form of predator-prey interaction.

\section{Effects propagating along the detritus-based chain}

Experimentation in a laboratory microcosm system tested the effects of predatory fish (Rutilus rutilus) on the foraging behavior of sediment-dwelling chironomids (Chironomus riparius) and on ecosystem properties such as the distribution and microbial decomposition of organic particles (Stief and Hölker 2006). Under natural conditions chironomids face a trade-off between foraging on organic matter at the sediment surface and reducing predation risk from Rutilus by retreating into burrows within the sediment. This behavioral shift has the potential to cause cascading effects on microbial decomposition of organic matter and so changes the distribution of organic and inorganic carbon and ammonium between the sediment and the water column.

In an attempt to emulate local conditions at the sediment-water column interface, Stief and Hölker (2006) collected fish, chironomids, and sediment for their experiments from natural freshwater bodies. Chironomids were reared in the laboratory using dried leaves collected from freshwater environments. The sediment, which contained microbes and organic particles, was poured into replicated microcosms in the laboratory to a depth that would enable chironomids to build burrows. The experiment evaluated the nonconsumptive effects of predators on ecosystem properties and functions using a recirculating flow system in which water was pumped from either aquaria holding individual Rutilus predators (predator cues) or from fishless (control) aquaria into microcosms containing chironomids and without chironomids.

The experiment showed that by retreating into burrows in response to predator cues, chironomids increased the amount of organic matter that entered the sediment relative to fishless controls because they carried food particles into their burrows and defecated within the burrows. This effect thereby increased the availability of organic matter within the sediment layer to be decomposed and mineralized and later taken up by aquatic vegetation. Under conditions in which chironomids did not face risk and in treatment conditions without chironomids, organic matter remained at the sediment surface and was broken down by microbes that in turn released organic and inorganic carbon and ammonium in dissolved form to the water column to be taken up by microbes and algae. This latter case resembles conditions that might also be expected if predator effects on chironomids were purely consumptive, i.e., a decline in chironomid abundance should lead to accumulation of organic matter at the sediment surface; whereas the predator-induced habitat shift reduced organic matter at the sediment surface. Thus, consumptive and nonconsumptive predator effects should lead to qualitatively different spatial distributions of resources within the aquatic system where predators with consumptive effects have limited net effects on decomposition and the redistribution of organic material. This hypothesis has yet to be tested because of the singular focus on nonconsumptive predator effects.

\section{Effects on trophic transfer efficiencies}

In addition to indirect effects flowing downward through food chains to affect ecosystem properties and functions, predator indirect effects may feed back upward to influence the biomass and quality of prey available to predators (Abrams 1992). This phenomenon may occur via changes in energy transfer efficiencies between trophic levels.

The influence of nonconsumptive predator effects on trophic transfer efficiency has been experimentally documented in a rocky intertidal ecosystem, where risk cues released by predatory green crabs (Carcinus maenas) modify the behavior and foraging rate of one of its principal prey, the carnivorous snail Nucella lapillus (Trussell et al. 2003, 2006a). This nonconsumptive effect, in turn, causes a trophic cascade by reducing the feeding impact of $N$. lapillus on barnacles. Mesocosm experiments that emulate the physical characteristics of rocky intertidal seashores were used to explore the relative importance of green crab predation risk and Nucella density (intraspecific competition) on Nucella ecological growth efficiency (the efficiency of converting acquired energy into snail biomass) (Trussell et al. 2006b). Both predation risk and conspecific density effects were quite strong and additive. Predation risk reduced growth efficiency by $44-76 \%$ and conspecific density reduced growth efficiency by $28-69 \%$. Although both effects were important, the effect, magnitude of predation risk, explained twice as much of the variation in growth efficiency as did conspecific density (32\% vs. $15 \%)$.

In contrast to classical views of trophic transfer efficiencies (Lindeman 1942, Odum and Biever 1984, Hairston and Hairston 1993), these results suggest that the efficiencies of species within an ecosystem are not fixed, but rather can be altered dramatically by predation risk. The mechanism(s) explaining the reduction in growth efficiency has not been completely resolved. A candidate explanation based on research in other aquatic systems (Rovero et al. 1999, McPeek et al. 2001) is that elevated stress levels in prey facing predation risk may increase prey metabolic costs and/or reduce their assimilation efficiencies. A change in either of these physiological traits will reduce the amount of energy consumed by Nucella that is converted into trophic biomass. Moreover, regardless of the mechanism, the poorer quality of prey stressed by predation 
risk (Abrams 1992) will ultimately reduce the amount of energy that is transferred further up the food chain. When the nonconsumptive predator effects predominate, there is the potential for reduced secondary production of higher trophic levels (relative to instances where consumptive effects are more important than risk effects). The increased attenuation of energy transfer and secondary production may provide a biological mechanism that contributes to the lack of energy flow up food chains, thus explaining why so many food chains are short (Elton 1927, Hutchinson 1959).

\section{Syntheses of Complementary Studies: Putting the Pieces Together}

The collections of studies presented in the following do not individually provide evidence for predator risk effects on ecosystem properties and function. Rather, by drawing linkages among several independent studies from the same ecosystems, they offer corroborating evidence that predation risk can influence ecosystem properties and functions.

\section{Effects propagating along the live plant-based chain}

Lake ecosystems.-Filter-feeding Daphnia routinely undergo vertical migration within the water column in lakes. A series of laboratory, mesocosm, and whole-lake experiments have demonstrated that filter-feeding by Daphnia and other zooplankton can alter whole-lake phytoplankton density (Paterson et al. 2002) and facilitate a large-scale trophic cascade (Carpenter and Kitchell 1996). Feeding in the phytoplankton-rich epilimnion of lakes, however, increases Daphnia exposure to an array of predatory fish (Riessen 1999). Daphnia exposed to water containing cues from such predators reduce predation risk by spending daylight hours in the colder hypolimnion, a region that also contains fewer phytoplankton. At dusk, Daphnia migrate upward to feed in the epilimnion during the night. Such diel vertical migration can have considerable costs with the potential for affecting ecosystem functions. Laboratory studies on six different Daphnia species showed that nonlethal exposure to predatory fish cues reduces filtering rate by $\sim 20 \%$ relative to a no-predator control, and that cue-free Daphnia were $\sim 10 \%$ longer than those exposed to predator cues. In another experiment, clones of D. magna exposed to fish cues and allowed to migrate vertically in a thermally stratified microcosom grew $0.27 \mathrm{mg} / \mathrm{d}$, vs. $0.57 \mathrm{mg} / \mathrm{d}$ for clones in the control treatment (Dawidowicz and Loose 1992). This predator-induced reduction in Daphnia body growth rate has the potential to reduce nutrient cycling rates because feeding rate in Daphnia is an exponential function of body size (Knoechel and Holtby 1986). Consequently, predator-induced changes in behavior, growth, and filtering rate have the potential to alter nutrient cycling rates in lakes where Daphnia and other small zooplankton are the primary consumers. Such trade-off behavior may break down, however, in warm shallow lakes that do not stratify by temperature and productivity, implying that the foraging-predation risk trade-off applies to a subset of colder, but thermally stratified lake systems. Moreover, diel vertical migration may be driven less by predation risk than by a trade-off between obtaining resources and seeking out optimal temperatures for development. Thus, while predation risk has the potential to drive ecosystem function, the context dependency of this phenomenon remains to be determined.

Stream ecosystems.-Diel vertical migration is one way in which nutrients may become redistributed in aquatic systems, especially those with a deep water column. In shallower aquatic systems such as streams, nutrients may become redistributed horizontally as a consequence of refuge seeking behavior of consumers living on the bottom of the water body.

Studies in New Zealand and North American streams suggest that the indirect effects of predatory fish on ecosystem processes may be driven by predator-induced changes in invertebrate grazer behavior. Simon et al. (2004) added stable isotopes to two streams in New Zealand, to trace the cascading effects of fish (trout [Salmo trutta] and galaxiads [Galaxias sp.]) on rates of nitrogen uptake and retention. They found that nitrogen uptake by the epilithon was up to six times higher in the presence of fish than in their absence. Moreover, much of that nitrogen was retained in the epilithon, and grazers had lower nitrogen in their body tissue in the presence of fish than in their absence. This study did not provide direct evidence of a nonconsumptive effect, but cited others to explain the pattern of $\mathrm{N}$-reallocation in their system. For example, McIntosh and Townsend (1996) experimentally demonstrated a behavioral trophic cascade from brown trout to mayfly (Deleatidium) grazing behavior to algal biomass and distribution. The presence of trout induced grazing mayflies to avoid the tops of cobbles, increasing algal biomass in those areas. Simon et al. (2004) argue that this direct nonconsumptive effect of predators on grazer behavior (suppression of grazing on algae) led to a reallocation of nitrogen retention among compartments of the ecosystem by increasing retention of nitrogen in the epilithon and reducing nitrogen retention by grazers.

Evidence from Colorado Rocky Mountain streams also supports the importance of a nonconsumptive cascade in which predatory fish (brook trout: Salvelinus fontinalis) affect the behavior of invertebrate grazers (mayflies) and influence ecosystem processes. Experiments in mesocosms established that chemical cues from brook trout cause changes in algal biomass as an indirect consequence of changes in mayfly grazer behavior (Peckarsky and McIntosh 1998), while wholestream experiments showed that fish-cue-induced changes in grazer foraging behavior affected resource (algal) patchiness (McIntosh et al. 2004). Recent experimentation has also resolved the link between nonconsumptive effects of trout via changes in mayfly feeding periodicity 
on the diel periodicity of organic and inorganic matter fluxes in Colorado streams (B. W. Taylor, B. L. Peckarsky, and A. R. McIntosh, unpublished manuscript). Five of 10 small fishless streams were manipulated by adding brook trout chemical cues (Peckarsky et al. 2002). The addition of fish cues changed the periodicity of the mobile mayfly grazers relative to fishless control streams (McIntosh et al. 2004), which in turn altered local export of suspended organic matter and affected nutrient levels as far as $30 \mathrm{~m}$ downstream from the fish cue addition (B. W. Taylor, B. L. Peckarsky, and A. R. McIntosh, unpublished manuscript).

Grassland ecosystems.-Disruption of grazing behavior through habitat shift may also affect the horizontal spatial distribution of nutrients and primary productivity of terrestrial grassland ecosystems. For instance, the Greater Yellowstone ecosystem has been the focus of a long-term experiment examining the impacts of grazing herbivores such as elk (Cervus elaphus) on ecosystem properties such as plant diversity, plant standing crop biomass, and stoichiometry, and functions such as net primary production (NPP) and nitrogen $(\mathrm{N})$ mineralization rate. The experiment compared ecosystem attributes in open plots that allowed grazer access to those of companion plots that excluded herbivores. Absence of grazing herbivores led to a $35 \%$ reduction in plant species diversity (Augustine and Frank 2001), a 22\% reduction in plant tissue $\mathrm{N}$ that caused a concomitant $24 \%$ rise in tissue C:N ratio (Tracy and Frank 1998), and a $53 \%$ reduction in $\mathrm{N}$ mineralization rate (Frank and Groffman 1998). Grazer absence also yielded a fourfold increase in plant standing crop, even though NPP decreased by 24\% (Tracy and Frank 1998). These results show that the absence of grazing increased the standing crop of a less diverse plant community that was lower in nutrient quality, and that this shift in nutrient quality led in turn to a slowing of $\mathrm{N}$-mineralization rate.

This research was conducted during a period when top predators were altogether absent from the ecosystem. In 1995, wolves (Canis lupus) were reintroduced to Yellowstone and transformed ecosystem attributes (Ripple and Beschta 2004). In particular, wolf presence caused elk to increase their proportional use of safe coniferous habitat at the expense of feeding in open grassland and aspen habitats (Ripple and Beschta 2004, Creel et al. 2005, Fortin et al. 2005). This behavioral shift led to a 3-19 fold reduction in herbivory and a 2-3 fold increase in plant growth in some foraging areas (Ripple and Beschta 2004). Wolves thus cause elk to redistribute themselves on the landscape and abandon certain foraging sites to avoid predation risk. The consequences of predator-induced changes in elk behavior on ecosystem properties are qualitatively similar to those observed between open areas and exclosures. As in the spider-grasshopper-old-field example, such qualitative effects would not be expected if wolves merely reduced elk densities.
There is, however, some uncertainty whether or not predator effects on local elk densities are largely determined by risk responses or by direct predation (Creel et al. 2005). Elk populations within the focal study region of Yellowstone declined by 6000 individuals (or $41 \%$ ) over the course of six years (Ripple and Beschta 2004, Creel et al. 2005). Given the known wolf density of 50 individuals (Ripple and Beschta 2004), each wolf would, on average, have had to kill one elk every two to three weeks. However, estimated predation rates in a similar, adjacent ecosystem type revealed that per capita kill rates of wolves range between one every 13 weeks to one every 32 weeks (Hebblewhite and Pletcher 2002). These estimates suggest that the majority of population decline in elk during this period arose from mechanisms other than direct mortality caused by predation. Strong candidate hypotheses, in light of evidence of elk movement (Ripple and Beschta 2004, Creel et al. 2005, 2007, Fortin et al. 2005), are that the declines were caused by elk shifting their entire range use in response to heightened predation risk, and that predation risk enhanced physiological stress and reduced fitness (physiological condition, reproduction, and non-predation mortality) in much the same way as for Nucella snails.

\section{Effects propagating along the detritus-based chain}

As with the case studies, we also found indirect evidence to suggest that nonconsumptive effects of predators can influence detritus-based chains. Konishi et al. (2001) deployed an experiment within natural streams containing leaf-shredding amphipods and fish. The four-week experiment compared organic matter loss from cages containing fish predators (trout and sculpins together) relative to cages without predators. Both the biomass of leaf-shredding amphipods and rates of leaf litter decomposition decreased in cages with fish relative to fishless controls. In the experimental system, the most dominant species of amphipod decreased in abundance when in the presence of fish, but the second-most abundant amphipod did not. However, leaf decomposition rates decreased when the amphipods were exposed to predatory fish. Because amphipods were able to immigrate and emigrate from the cages, the experimental design could not resolve whether the direct effect on the biomass of the dominant amphipod was entirely due to predation or to a habitat shift in response to predation risk. However, the lack of a density reduction of the second most abundant amphipod suggests that there may be a strong risk component driving the dynamics. The authors draw further support for this assertion from other studies (Andersson et al. 1986, Holomuzki and Hoyle 1990) that have shown that amphipods obtain refuge from predators by retreating to the interstices between rocks and that they will move away from high risk areas to avoid fish predation altogether. The fact that amphipods change their behavior in the presence of sculpins supports the 
speculation that the mechanism of the indirect effect of sculpins on leaf litter decomposition rates may be driven by risk effects or the interplay between risk and density effects.

\section{Effects on net ecosystem energy flux}

Many aquatic ecosystems are largely heterotrophic because organic carbon sources are produced both in situ and from external sources. One potentially important source of carbon input to pond ecosystems is the seasonal influx of organisms having complex life cycles that require them to reproduce in aquatic habitats (i.e., aquatic insects, amphibians). However, many of these taxa will avoid colonizing aquatic habitats that contain predator cues (Sih et al. 1988, Resetarits and Wilbur 1989, Blaustein and Kotler 1993, Binckley and Resetarits 2005).

Such predator-induced shifts in habitat selection may have important implications for subsidies (energy flux) between aquatic and terrestrial habitats. For example, an experiment conducted over 10 years showed that the number of egg masses laid by spotted salamanders (Ambystoma maculatum) in ponds stocked with fish was less than one-half the number laid in fishless ponds (Petranka and Holbrook 2006). This species can be responsible for $45-99 \%$ of pond inputs for the entire salamander assemblage (Regester et al. 2006). After accounting for export of energy from hatchling salamanders migrating out of the pond to the surrounding land matrix, the authors estimated that there was a net energy flow into the aquatic habitat, with net flux due to A. maculatum equaling 136-760 g ash-free dry mass/yr for permanent fishless ponds. Consequently, predatorinduced avoidance of ponds by salamanders can reduce these fluxes by $\sim 50 \%$ (Regester et al. 2006).

\section{Discussion}

It has been suggested for some time that the large divide between evolutionary and ecosystem ecology limits our progress in achieving a predictive understanding of ecosystem function (Levin 1992). Failure to bridge this divide would be unfortunate because an evolutionary perspective may be necessary to understand how organismal traits (including behavior and physiology) determine the ability of organisms to respond to environmental context and hence influence the nature of local ecosystem properties and functions. Such insights are sorely needed to begin resolving the relationship between the diversity of species in ecosystems and attendant ecosystem functions (Chapin et al. $2000 b$, Hooper et al. 2005). The biggest challenge in actively linking evolutionary and ecosystem ecology is to identify operational ways of blending the two perspectives (Levin 1992, Holt 1995, Carpenter and Turner 2000).

We have shown here that one important trait, adaptive consumer foraging behavior, has much potential to link evolutionary and ecosystem ecological processes through a mechanism that is relevant to both levels of resolution. That mechanism is the fundamental need to balance a trade-off between obtaining energy and nutrients for individual production and avoiding being a resource for other consumers. The advantage of applying an evolutionary ecological perspective is the inherent recognition that this trade-off is flexible and thereby offers a way to predict how local ecological context affects the nature and magnitude of trophic interactions and consequent ecosystem properties and functions.

Explicit experimental tests of this trade-off have often reported outcomes that run counter to conventional ideas about ecosystem functioning based on a classic ecosystems ecology perspective that assumes predator indirect effects on resources are mediated by changes in prey density due to consumption (a consumptive effect). For example, assumed consumptive mechanisms underlie the predictions that trophic cascades should be strongest in aquatic systems (Strong 1992), that there should be positive relationships between plant species diversity and ecosystem functions such as primary productivity and elemental cycling, and that trophic transfer efficiencies are fixed and determined by the quality and production of resources flowing up the trophic chain. A perspective incorporating consumptive and nonconsumptive mechanisms provides a more comprehensive picture of the links between predators and ecosystem functions, and may help to reconcile the yet-unexplained observation (Wardle 2002) that in some systems consumers enhance functions such as productivity and elemental cycling, whereas in other systems consumers reduce the level of those functions. Our synthesis also suggests that the notion that ecosystems are either controlled from the top down by predators or from the bottom up by nutrient supply and primary production may be an oversimplification. Top-down nonconsumptive effects of predators may feed back upward to mediate the strength of bottom-up control on higher trophic levels. Such interplay between top-down and bottom-up effects can be better predicted once we gain clearer insight into the ways that behavioral effects propagate within ecosystems.

In the process of compiling this review we found many studies examining trophic control of ecosystem processes that did not resolve whether predator indirect effects were mediated by consumptive or nonconsumptive effects. In those cases distinction of mechanisms of effects and explanations for unexpected outcomes were relegated to speculation. This kind of speculation can be reduced if we design experiments to test explicit predictions based on both consumptive and nonconsumptive mechanisms, which can have qualitatively different effects on ecosystem functions. In order to stimulate research that simultaneously examines consumptive and nonconsumptive mechanisms, we present some preliminary predictions on the relative nature of consumptive and nonconsumptive effects (Fig. 1), based 
Topology

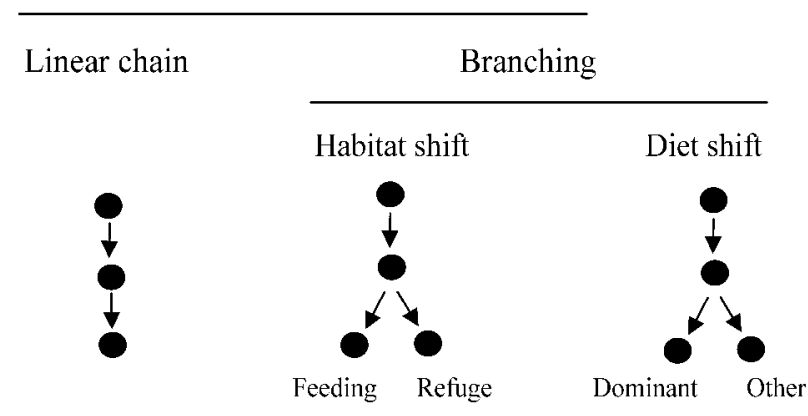

Ecosystem property

Trophic transfer efficiency

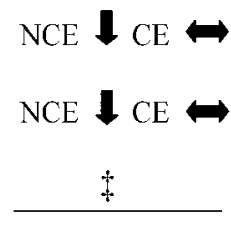

$\mathrm{NCE} \downarrow \mathrm{CE} \mapsto \dagger$

$\mathrm{NCE} \downarrow \mathrm{CE} \leftrightarrow$

Food chain length

Plant species diversity

$\mathrm{NCE} \downarrow \mathrm{CE}$

$\mathrm{NCE} \downarrow \mathrm{CE} \Leftrightarrow$

$\mathrm{NCE} \downarrow \mathrm{CE}$

$\mathrm{NCE} \mathbf{C E} \leftrightarrow$

Ecosystem function

Aboveground NPP
Plant decomposition
N cycling/mineralization

$?$

$\mathrm{NCE} \downarrow \mathrm{CE}$

$\mathrm{NCE}+\mathrm{CE}$ ?

$\mathrm{NCE} \downarrow \mathrm{CE} \downarrow$

$\mathrm{NCE} \mathrm{CE} \Leftrightarrow$

?

$?$

$\mathrm{NCE} \downarrow \mathrm{CE}$

$\mathrm{NCE} \mathrm{CE}$ ?

FIG. 1. Predicted predator indirect effects on ecosystem properties and functions precipitated either by predator-caused changes in herbivore density (a consumptive effect, CE) or changes in herbivore adaptive foraging (a nonconsumptive effect, NCE). Directional predictions are relative to a two-level plant-herbivore reference system. NPP is net primary productivity. The $\uparrow$ symbol indicates that the effect is in feeding habitat; the $\$$ symbol indicates no diversity of plants by the definition of linear topology.

on our findings from the literature synthesis. Some of these predictions vary with food chain topology (linear vs. branching) because the nature of many nonconsumptive effects is dependent on topology (i.e., whether predators cause a time budget shift vs. habitat or diet shift of prey). The directions of predicted cascading effects of predators on various ecosystem properties and functions are presented in Fig. 1 by comparison between systems in which predators are absent (two-level plantherbivore or organic matter-decomposer reference system) and systems where they are present (three-level predator-herbivore-plant or predator-decomposerorganic matter system).

We predict that in many cases nonconsumptive effects of predators on ecosystem properties such as trophic transfer efficiency, food chain length, and plant species diversity will be qualitatively different from consumptive predator effects (Fig. 1). In some cases, there are differences in the direction of effect propagated by the same kinds of predators (e.g., nonconsumptive effects on plant diversity) because of dependencies on food web topology. Whenever predators cause prey to leave a foraging site (habitat shift), the prey no longer mediate competitive interactions among plants. This leads to dominance by a few plant species. However, predators causing prey diet shifts end up causing prey to mediate competitive dominance and hence indirectly enhance plant diversity.

We are less certain how to predict the direction of consumptive and nonconsumptive indirect effects on ecosystem functions such as net primary production (NPP), plant matter decomposition, and nitrogen $(\mathrm{N})$ cycling and mineralization, simply because many cases (especially for consumptive effects) have not been examined empirically (Fig. 1). From cases where information does exist, we predict that nonconsumptive predator effects should decrease aboveground NPP and plant decomposition, and either increase or decrease $\mathrm{N}$ mineralization (depending on food chain typology) relative to conditions where they are absent, but case studies for predators with consumptive effects are insufficient to offer comparable predictions at this time (Fig. 1).

We find that top predators can have cascading effects that influence community composition of ecological systems as well as ecosystem properties and functions. 
We find, however, that strong cascading effects may be more likely to occur in systems where predators largely induce adaptive behavioral responses of their prey rather than largely reduce prey density. Given that most prey in food chains exhibit some form of adaptive response to their predators (Werner and Peacor 2003, Schmitz et al. 2004, Preisser et al. 2005), we argue that linking adaptive foraging with ecosystem function may extend our ability to explain variety in the nature and strength of trophic effects on ecosystem properties and functions beyond current perspectives that assume predator effects are merely consumptive. Combining consumptive and nonconsumptive perspectives should enable us to explain a much broader range of outcomes and contingencies about trophic control by predators.

\section{ACKNOWLEDGMENTS}

This work was conducted as part of the "Does Fear Matter?" Working Group supported by the National Center for Ecological Analysis and Synthesis (NSF Grant DEB-0072909) and the University of California, Santa Barbara. We thank J. E. Duffy and an anonymous reviewer for comments.

\section{Literature Cited}

Abrams, P. A. 1984. Foraging time optimization and interactions in food webs. American Naturalist 124:80-96.

Abrams, P. A. 1992. Predators that benefit prey and prey that harm predators: unusual effects of interacting foraging adaptations. American Naturalist 140:573-600.

Andersson, K., C. Brönmark, J. Hermann, B. Malmqvist, C. Otto, and P. Sjöström. 1986. Presence of sculpins (Cottus gobio) reduces drift and activity of Gammarus pulex (Amphipoda). Hydrobiologia 133:209-215.

Augustine, D. J., and D. A. Frank. 2001. Effects of migratory grazers on spatial heterogeneity of soil nitrogen properties in a grassland ecosystem. Ecology 82:3149-3162.

Belovsky, G. E., and J. B. Slade. 2000. Insect herbivory accelerates nutrient cycling and increases plant production. Proceedings of the National Academy of Sciences (USA) 97: 14412-14417.

Binckley, C. A., and W. J. Resetarits. 2005. Habitat selection determines abundance, richness and species composition of beetles in aquatic communities. Biology Letters 1:370-374.

Blaustein, L., and B. P. Kotler. 1993. Oviposition habitat selection by the mosquito, Culiseta longiareolata: effects of conspecifics, food and green toad tadpoles. Ecological Entomology 18:104-108.

Carpenter, S. R., R. Defries, T. Dietz, H. A. Mooney, S. Polasky, W. V. Reid, and R. J. Scholes. 2006. Millennium ecosystem assessment: research needs. Science 314:247-256.

Carpenter, S. R., and J. Kitchell, editors. 1996. The trophic cascade in lakes. Cambridge University Press, Cambridge, UK.

Carpenter, S. R., and M. G. Turner. 2000. Hares and tortoises: interactions of fast and slow variables in ecosystems. Ecosystems 3:495-497.

Chapin, F. S., P. Mattson, and H. Mooney. 2000a. Ecology of terrestrial ecosystems. Springer Verlag, New York, New York, USA.

Chapin, F. S., B. H. Walker, R. J. Hobbs, D. U. Hooper, J. H. Lawton, O. E. Sala, and D. Tilman. 1997. Biotic control over the functioning of ecosystems. Science 277:500-504.

Chapin, F. S., E. S. Zavaleta, V. T. Eviner, R. L. Naylor, P. M. Vitousek, H. L. Reynolds, D. U. Hooper, S. Lavorel, O. E. Sala, S. E. Hobbie, M. C. Mack, and S. Diaz. $2000 b$. Consequences of changing diversity. Science 405:234-242.
Creel, S., D. Christianson, S. Liley, and J. A. Winnie. 2007. Predation risk affects reproductive physiology and demography of elk. Science 315:960.

Creel, S., J. Winnie, B. Maxwell, K. Hamlin, and M. Creel. 2005. Elk alter habitat selection as an antipredator response to wolves. Ecology 86:3387-3397.

Dawidowicz, P., and C. Loose. 1992. Cost of swimming by Daphnia during diel vertical migration. Limnology and Oceanography 37:665-669.

DeAngelis, D. L. 1992. Dynamics of nutrient cycling and food webs. Chapman and Hall, New York, New York, USA.

Duffy, J. E. 2003. Biodiversity loss, trophic skew, and ecosystem functioning. Ecology Letters 6:680-687.

Elton, C. 1927. Animal ecology. Sidgwick and Jackson, London, UK.

Fortin, D., H. L. Beyer, M. S. Boyce, D. W. Smith, T. Duchesne, and J. S. Mao. 2005. Wolves influence elk movements: behavior shapes a trophic cascade in Yellowstone National Park. Ecology 86:1320-1330.

Frank, D. A., and P. M. Groffman. 1998. Ungulate vs. landscape control of soil $\mathrm{C}$ and $\mathrm{N}$ processes in grasslands of Yellowstone National Park. Ecology 79:2229-2241.

Fukami, T., D. A. Wardle, P. J. Bellingham, C. P. H. Mulder, D. R. Towns, G. W. Yeates, K. I. Bonner, M. S. Durrett, M. N. Grant-Hoffman, and W. M. Williamson. 2006. Above- and below-ground impacts of introduced predators in seabird-dominated island ecosystems. Ecology Letters 9: 1299-1307.

Greig, H. S., and A. R. McIntosh. 2006. Indirect effects of predatory trout on organic matter processing in detritusbased stream food webs. Oikos 112:31-40.

Hairston, N. G., Jr., and N. G. Hairston, Sr. 1993. Cause-effect relationship in energy flow, trophic structure and interspecific interactions. American Naturalist 142:379-411.

Hargrave, C. W. 2006. A test of three alternative pathways for consumer regulation of primary productivity. Oecologia 149: 123-132.

Hebblewhite, M., and D. Pletcher. 2002. Effects of elk group size on predation by wolves. Canadian Journal of Zoology 80:800-809.

Holomuzki, J. R., and J. D. Hoyle. 1990. Effect of predatory fish presence on habitat use and diel movement of a stream amphipod, Gammarus minus. Freshwater Biology 24:509517.

Holt, R. D. 1995. Linking species and ecosystems: where is Darwin? Pages 1273-1280 in C. Jones and J. H. Lawton, editors. Linking species and ecosystems. Chapman and Hall, London, UK.

Hooper, D. U., F. S. Chapin, J. J. Ewel, A. Hector, P. Inchausti, S. Lavorel, J. H. Lawton, D. M. Lodge, M. Loreau, S. Naeem, B. Schmid, H. Setala, A. J. Symstad, J. Vandermeer, and D. A. Wardle. 2005. Effects of biodiversity on ecosystem functioning: a consensus of current knowledge. Ecological Monographs 75:3-35.

Hutchinson, G. E. 1959. Homage to Santa Rosalia; or why are there so many kinds of animals? American Naturalist 93:145159.

Knoechel, R., and L. Holtby. 1986. Cladoceran filtering rate body length relationships for bacterial and large algal particles. Limnology and Oceanography 31:195-200.

Konishi, M., S. Nakano, and T. Iwata. 2001. Trophic cascading effects of predatory fish on leaf litter processing in a Japanese stream. Ecological Research 16:415-422.

Leopold, A. 1939. A biotic view of the land. Journal of Forestry 37:727-730.

Levin, S. A. 1992. The problem of pattern and scale in ecology. Ecology 73:1943-1967.

Lima, S. L. 1998. Nonlethal effects in the ecology of predatorprey interactions. What are the ecological effects of antipredator decision-making? BioScience 48:25-34. 
Lima, S. L., and L. M. Dill. 1990. Behavioral decisions made under the risk of predation. Canadian Journal of Zoology 68: 619-640.

Lindeman, R. L. 1942. The trophic-dynamic aspect of ecology. Ecology 22:399-418.

Mangel, M., and C. W. Clark. 1988. Dynamic modeling in behavioral ecology. Princeton University Press, Princeton, New Jersey, USA.

Maron, J. L., J. A. Estes, D. A. Croll, E. M. Danner, S. C. Elmendorf, and S. L. Buckelew. 2006. An introduced predator alters Aleutian Island plant communities by thwarting nutrient subsidies. Ecological Monographs 76:324.

McInnes, P. J., R. J. Naiman, J. Pastor, and Y. Cohen. 1992. Effects of moose browsing on vegetation and litter of the boreal forest, Isle Royale, Michigan, USA. Ecology 73:20592075.

McIntosh, A. R., B. L. Peckarsky, and B. W. Taylor. 2004. Predator-induced resource heterogeneity in a stream food web. Ecology 85:2279-2290.

McIntosh, A. R., and C. R. Townsend. 1996. Interactions between fish, grazing invertebrates and algae in a New Zealand stream: a trophic cascade mediated by fish-induced changes to grazer behaviour? Oecologia 108:174-181.

McPeek, M. A., M. Grace, and J. M. L. Richardson. 2001. Physiological and behavioral responses to predators shape the growth/predation risk trade-off in damselflies. Ecology 82:1535-1545.

Odum, E. P., and L. J. Biever. 1984. Resource quality, mutualism, and energy partitioning in food chains. American Naturalist 131:424-444.

Oksanen, L. 1988. Ecosystem organization: mutualism and cybernetics or plain Darwinian struggle for existence. American Naturalist 131:424-444.

Paine, R. T. 1988. Food webs: road maps of interactions or grist for theoretical development. Ecology 69:1648-1654.

Pastor, J., B. Dewey, R. J. Naiman, P. F. McInnes, and Y. Cohen. 1993. Moose browsing and soil fertility in the boreal forests of Isle Royale National Park. Ecology 74:467-480.

Paterson, M., D. Findlay, A. Salki, L. Hendzel, and R. Hesslein. 2002. The effects of Daphnia on nutrient stoichiometry and filamentous cyanobacteria: a mesocosm experiment in a eutrophic lake. Freshwater Biology 47:1217-1233.

Peckarsky, B. L., S. D. Cooper, and A. R. McIntosh. 1997. Extrapolating from individual behavior to populations and communities in streams. Journal of the North American Benthological Society 16:375-390.

Peckarsky, B. L., and A. R. McIntosh. 1998. Fitness and community consequences of avoiding multiple predators. Oecologia 113:565-576.

Peckarsky, B. L., A. R. McIntosh, B. W. Taylor, and J. Dahl. 2002. Predator chemicals induce changes in mayfly lifehistory traits: a whole-stream manipulation. Ecology 83:612618.

Petranka, J. W., and C. T. Holbrook. 2006. Wetland restoration for amphibians: should local sites be designed to support metapopulations or patchy populations? Restoration Ecology 14:404-411.

Preisser, E., D. Bolnick, and M. Benard. 2005. The high cost of fear: behavioral effects dominate predator-prey interactions. Ecology 86:501-509.

Regester, K. J., K. R. Lips, and M. R. Whiles. 2006. Energy flow and subsidies associated with the complex life cycle of ambystomid salamanders in ponds and adjacent forests in southern Illinois. Oecologia 147:303-314.

Resetarits, W. J., and H. M. Wilbur. 1989. Choice of oviposition site by Hyla chrysoscelis: role of predators and competitors. Ecology 70:220-228.
Riessen, H. 1999. Predator-induced life history shifts in Daphnia: a synthesis of studies using meta-analysis. Canadian Journal of Fisheries and Aquatic Sciences 56:2487-2494.

Ripple, W. J., and R. L. Beschta. 2004. Wolves and the ecology of fear: can predation risk structure ecosystems? BioScience 54:755-766.

Ritchie, M. E., D. Tilman, and J. M. H. Knopps. 1998. Herbivore effects on plant and nitrogen dynamics in oak savanna. Ecology 79:165-177.

Rovero, F., R. N. Hughes, and G. Chelazzi. 1999. Cardiac and behavioural responses of mussels to risk of predation by dogwhelks. Animal Behaviour 58:707-714.

Schmitz, O. J. 2004. From mesocosms to the field: the role and value of cage experiments in understanding top-down effects in ecosystems. Pages 277-302 in W. W. Weisser and E. Siemann, editors. Insects and ecosystem function. Springer Series in Ecological Studies. Springer-Verlag, Berlin, Germany.

Schmitz, O. J. 2006. Predators have large effects on ecosystem properties by changing plant diversity not biomass. Ecology 87:1432-1437.

Schmitz, O. J., O. Ovadia, and V. Krivan. 2004. Trophic cascades: the primacy of trait-mediated interactions. Ecology Letters 7:153-163.

Schmitz, O. J., and K. B. Suttle. 2001. Effects of top predator species on the nature of indirect effects in an old field food web. Ecology 82:2072-2081.

Sih, A., J. W. Petranka, and L. B. Kats. 1988. The dynamics of prey refuge use: a model and tests with sunfish and salamander larvae. American Naturalist 132:463-483.

Simon, K. S., C. R. Townsend, B. J. F. Biggs, W. B. Bowden, and R. D. Frew. 2004. Habitat-specific nitrogen dynamics in New Zealand streams containing native or invasive fish. Ecosystems 7:777-792.

Stief, P., and F. Hölker. 2006. Trait-mediated indirect effects of predatory fish on microbial mineralization in aquatic sediments. Ecology 87:3152-3159.

Strong, D. R. 1992. Are trophic cascades all wet? Differentiation and donor control in a speciose system. Ecology 73: 747-754.

Tansley, A. G. 1935. The use and abuse of vegetational concepts and terms. Ecology 16:284-307.

Tilman, D. 1989. Discussion: population dynamics and species interactions. Pages 89-100 in J. Roughgarden, R. M. May, and S. A. Levin, editors, Perspectives in ecological theory. Princeton University Press, Princeton, New Jersey, USA.

Tracy, B. J., and D. A. Frank. 1998. Herbivore influence on soil microbial biomass and nitrogen mineralization in a northern grassland ecosystem: Yellowstone National Park. Oecologia 114:556-562.

Trussell, G. C., P. J. Ewanchuk, and M. D. Bertness. 2003. Trait-mediated indirect effects in rocky intertidal food chains: predator risk cues alter prey feeding rates. Ecology 84:629-640.

Trussell, G. C., P. J. Ewanchuk, and C. M. Matassa. $2006 a$. Habitat effects on the relative importance of trait- and density mediated indirect interactions. Ecology Letters 9: $1245-1252$.

Trussell, G. C., P. J. Ewanchuk, and C. M. Matassa. $2006 b$. The fear of being eaten reduces energy transfer in a simple food chain. Ecology 87:2979-2984.

Wardle, D. A. 2002. Communities and ecosystems: linking the aboveground and belowground components. Princeton University Press, Princeton, New Jersey, USA.

Werner, E. E., and S. D. Peacor. 2003. A review of traitmediated indirect interactions in ecological communities. Ecology 84:1083-1100. 